\title{
Risk estimation for carcinogens based on epidemiological data: A structured approach, illustrated by an example on chromium
}

\author{
R. Alexandra Goldbohm ${ }^{\text {a,* }}$, Erik L.J.P. Tielemans ${ }^{\text {a }}$, Dick Heederik ${ }^{\mathrm{b}}$, Carina M. Rubingh ${ }^{\mathrm{a}}$, \\ Susan Dekkers ${ }^{\text {a }}$, Marianne I. Willems ${ }^{\text {a }}$, E. Dinant Kroese ${ }^{\text {a }}$ \\ ${ }^{\text {a } T N O}$ Quality of Life, Business Unit Food \& Chemical Risk Analysis, Zeist, The Netherlands \\ ${ }^{\mathrm{b}}$ Institute for Risk Assessment Sciences, Division of Environmental and Occupational Health, Utrecht University, Utrecht, The Netherlands
}

Received 7 November 2005

Available online 23 February 2006

\begin{abstract}
It is generally recognized that human, epidemiological data, if available, are preferred as the starting point for quantitative risk analysis above the use of data from animal studies. Although methods to obtain proper risk estimates from epidemiological data are available, several impediments prevent their widespread application. These impediments include unfamiliarity with epidemiological methods and the lack of a structured and transparent approach. We described a framework to conduct quantitative cancer risk assessment based on epidemiological studies in a structured, transparent, and reproducible manner. Important features of the process include a weight-of-theevidence approach, estimation of the optimal exposure-risk function by fitting a regression model to the epidemiological data, estimation of uncertainty introduced by potential biases and missing information in the epidemiological studies, and calculation of excess lifetime risk through a life table to take into account competing risks. Sensitivity analyses are a useful tool to obtain insight into the impact of assumptions made and the variability of the underlying data. The framework is sufficiently flexible to allow many types of data, ranging from published, sometimes incomplete data to detailed individual data, while maintaining an optimal result, i.e., a state-of-the-art risk estimate with confidence intervals, based on all available evidence of sufficient quality.
\end{abstract}

(C) 2006 Elsevier Inc. All rights reserved.

Keywords: Risk assessment; Epidemiology; Uncertainty; Variability; Sensitivity analysis; Probabilistic; Potency; Excess lifetime risk; Chromium; Lung cancer

\section{Introduction}

Quantitative analysis of cancer risks associated with (occupational) exposure to carcinogens and the establishment of a risk estimate play an important role for risk characterization of carcinogenic chemicals (Sanner et al., 2001; U.S. Environmental Protection Agency, 2005). It is generally recognized that human data from epidemiological studies, if available, are preferred as the starting point for quantitative risk analysis of carcinogens above the use of data from experimental animal studies. This is, because

\footnotetext{
* Corresponding author. Fax : +31 306944070.

E-mail address: bausch@voeding.tno.nl (R.A. Goldbohm).
}

effects observed in animal species have to be translated into effects expected in humans, i.e., an extrapolation step is needed that not only is substantially uncertain, but also, from a precautionary principle approach, has to be conservative in nature (Vermeire et al., 1999). Besides the advantage that epidemiological data relate to the same species (i.e., man), the most important other advantages of epidemiological data over animal data are that exposure conditions and other circumstances that may modify the risk are usually much more comparable to those in the target population than those simulated in an animal experiment. Quantitative risk assessment based on epidemiological studies entails therefore substantially less uncertainty than if based on animal models, irrespective of some inherent uncertainties introduced by the epidemiological design itself. 
Despite the availability of epidemiological data, emphasis used to be on calculating cancer risks from experimental animal data. One of the reasons is that a clear, transparent, and generally accepted protocol for calculating cancer risk from epidemiological data is not available, despite substantial and important contributions to the development of epidemiological risk-assessment methods from distinguished scientists, e.g., Hertz-Picciotto and $\mathrm{Hu}, 1994$; Hertz-Picciotto, 1995; Moolgavkar et al., 1999; Samet et al., 1998; Shore, 1995; Stayner et al., 1995, 1999a,b, 2000; Steenland and Deddens, 2004; van Wijngaarden and Hertz-Picciotto, 2004. The relative complexity of issues involved in epidemiological data analysis also hampers acceptation by non-epidemiologists.

This situation is illustrated by the case of hexavalent chromium. In several reports, quantitative risk assessments are based on epidemiological data on exposure to chromium and lung cancer (Canadian Environmental Protection Act, 1994; Dutch Expert Committee on Occupational Standards, 1998; European Union Risk Assessment Report, 2002; Scientific Committee on Occupational Exposure Limits, 2003; Sorahan et al., 1998b; U.S. Environmental Protection Agency, 1998; WHO, 2000a). These reports differ with respect to the epidemiological data sets used and the methods applied. As a result, the risk estimates differ as well, sometimes substantially. Such different risk estimates do not pose a problem as such, as they are by nature derived with substantial uncertainty. More troubling, however, is that the multitude of choices, assumptions, and extrapolations, which are inherent in risk assessment, were often not motivated or made explicit. For this reason, it is difficult - not only for toxicologists and regulators, but also for most epidemiologists - to follow, interpret, compare and evaluate these risk assessments.

The objective of the present paper is to describe and discuss a systematic approach to quantitative risk assessment based on epidemiological data, focusing on the purpose and the essential features of the consecutive steps in the process. The steps include selection and evaluation of epidemiological data, derivation of a relative risk as function of exposure from the selected epidemiological data and calculation of excess lifetime risk for an exposed target population of interest. The approach is illustrated by the derivation of an excess lifetime risk estimate of lung cancer for exposure to hexavalent chromium, using different data sets and options. The approach is compared with some of the available quantitative risk assessments for hexavalent chromium. For a better comprehension of the risk estimation approach based on epidemiological data, some critical aspects, such as epidemiological study design, frequently used risk parameters, and exposure assessment in epidemiological studies are discussed first.

As hazard characterization is the main focus of this paper, hazard identification from epidemiological studies will not be discussed. The focus is on derivation of excess lifetime risks for the worker population, but the principles can equally be applied to other populations.
We hope that this systematic approach stimulates the use of existing epidemiological data and the conduct of new studies for the purpose of risk assessment for carcinogens and also enhances confidence in their use.

\section{Basic epidemiological concepts}

\subsection{Epidemiological study design}

In animal experiments efforts are made to generate genetically and environmentally homogeneous conditions except for the factor under study. Such conditions are usually not found in epidemiological studies. Human populations are heterogeneous in behavior and genetic susceptibility. Epidemiological, observational studies take this real life situation into account and conclude from it with respect to disease risk. Observational studies, where persons have not been randomly assigned to exposed versus unexposed groups, may be affected by confounding, which distorts the exposure-disease association. Confounding can occur because study participants also differ in many other aspects relating to exposure. In experimental studies, random allocation of subjects to different treatments will minimize the effect of this variation. In observational studies, random allocation to exposure is not possible. Instead, epidemiologists make use of many methods - in the design and in the statistical analysis of an observational study - to minimize most sources of bias and confounding. ${ }^{1}$ High quality studies are usually those in which such methods are appropriately applied and biases are quantified. For the purpose of epidemiological risk assessment, two different types of observational studies are the most relevant: cohort or follow-up studies and case-control studies (see text boxes).

\subsection{Risk, rate, relative risk, and excess risk}

To non-epidemiologists, the concepts of risk, rate, and the effect measures as used in epidemiology are always a source of much confusion. A basic comprehension of these concepts is necessary to understand how epidemiological studies can be used for risk assessment in a way comparable to animal studies. Without using mathematical formulas, an explanation and comparison of the key concepts and their application will be given below. A summary of these concepts is given in Table 1.

Risk refers to a person and is defined as the probability for that person to get (or die of) the disease of interest during a specific time period. This time period may be lifetime, up to a certain age (e.g., 75), or starting and ending at specified ages. Since it is impossible to measure a probability in a person, we measure risk among a larger group of people.

\footnotetext{
${ }^{1}$ It is outside the scope of this paper to discuss all potential biases and the possible solutions to be applied to avoid such biases. Epidemiologists are trained to discern potential methodological problems in studies and to assess the suitability of any chosen solutions.
} 


\section{Cohort studies}

Cohort studies start with a population initially free of the health outcome under study. Exposure is assessed at the start of the study (and is sometimes repeated during follow-up) and may include questionnaire/interview data, information from employee files, exposure monitoring data, and also the collection of biological materials. During follow-up, some subjects develop the disease (or other health outcome) and most others do not. The risk of developing the disease is related to the exposure, and generally expressed in terms of relative risk or relative rate, comparing risks (rates) among exposed and unexposed individuals. For an explanation of risks and rates, see main text. A main advantage of the cohort design is that at entry, subjects are free of the disease in question. Therefore, the disease will not influence exposure (information) of the subjects. To be sure about this, cases diagnosed in the first few years of follow-up may be excluded to avoid possible information bias due to preclinical disease. Due to the long latency period of cancer substantial follow-up time is required for a cohort study. The total time between the relevant exposure period and the end of the study should be sufficient to cover the time span necessary for a tumor that is caused by such exposure to develop into a clinically detectable tumor (or even to cause death when the study is based on mortality as endpoint).

\section{Case-control studies}

In contrast to cohort studies, case-control studies start with a group of patients, or persons known to have the disease or condition under study. These cases are compared with a control group, selected to represent the population from which the cases arose with respect to the exposures of interest. The exposure information is collected concerning a defined time prior to diagnosis of the disease. A case-control study usually compares the odds of past exposure to a suspected risk factor between cases and controls to obtain an odds ratio, which is an estimate of the relative risk (Table 1). An advantage compared to the cohort design is that no long follow-up period is required to get results. A second advantage is that for rare diseases, a much smaller sample size is needed, while the odds ratio is a very close approximation of the relative risk. A main disadvantage of case-control studies is that the disease can influence exposure information provided by the subjects ("recall bias") or recent exposure really is diVerent from what it used to be, because of the disease ("presence-of-disease bias"). For example, someone with cancer may (consciously or unconsciously) exaggerate his perceived exposure to certain chemicals because he wants to blame someone or something for his disease. Another form of bias that can be present in case-control studies is "selection bias", which can occur as a consequence of improper selection of study participants. Selection bias is present when the relationship between exposure and disease is different in those subjects actually involved in the study from those who theoretically were eligible to participate, (thus, including those who in the end did not participate). Low response rates in cases and/or an inappropriate choice of the control group may give some indication on the possible presence of selection bias.

Risk is measured as the number of subjects developing disease during a time period divided by the number of subjects followed for the time period and represents the average risk of disease in the population (Rothman, 2002).
For practical reasons, risk is hard to measure directly in studies on chronic disease. This is, because a population of human subjects, whether they are participants in an epidemiological study or members of the general

Table 1

Comparison of parameters to describe incidence and mortality and their derived measures of association

\begin{tabular}{|c|c|c|c|c|c|}
\hline Parameter & Synonyms & Type & Unit & Range & Proxies \\
\hline Risk & $\begin{array}{l}\text { Absolute risk } \\
\text { Cumulative incidence/mortality } \\
\text { Incidence/mortality proportion }\end{array}$ & Probability, proportion & - & {$[0,1]$} & Cumulative rate \\
\hline Rate & $\begin{array}{l}\text { Incidence/mortality rate } \\
\text { Hazard rate }\end{array}$ & $\frac{\text { Number of cases }}{\text { person years }}$ & Time $^{-1}$ & {$[0,>1]$} & Incidence density \\
\hline Relative risk (RR) & Risk ratio & Ratio of risks & - & {$[0, \infty]$} & $\begin{array}{l}\text { Rate ratio, Incidence density ratio, } \\
\text { Standardized ratio (SIR, SMR), Odds ratio (OR) }\end{array}$ \\
\hline Excess risk & $\begin{array}{l}\text { Risk difference } \\
\text { Added risk } \\
\text { Additive risk }\end{array}$ & Difference of risks & - & {$[-1,1]$} & \\
\hline
\end{tabular}


population in a defined geographic area, is almost never observed during their entire life span, simply because this would take much too long and part of the population will die of other causes in the meantime. For diseases such as chronic diseases, which can occur in principle anytime during someone's life, frequency of occurrence of the disease in a population can be directly observed by the number of subjects developing disease divided by the total time experienced for the subjects followed (Rothman, 2002). This parameter is called rate and is applicable to incidence (number of new cases of the disease detected) or mortality (number of cases died as a result of the disease). The 'total time experienced' is expressed as 'person years.' The rate is the basic parameter used in cohort studies as well as in registries such as cancer registries and in mortality statistics. Comparison of rates between populations is possible if these rates are stratified for age (i.e., divided in 1- or 5-year age groups) or standardized or adjusted for age.

The purpose of most epidemiological studies, as in experimental studies, is not to establish rates or risk for the population investigated, but to assess an association between exposure and disease. Epidemiological studies almost always use the ratio of two rates (e.g., rate among exposed group divided by rate among unexposed group) to express the magnitude of the association. This is because the ratio, unlike the underlying rates, is independent on the height of the rates compared. This property is important because most cancer incidence and mortality rates strongly increase with age. The rate ratio is also equivalent to the risk ratio or relative risk. The standardized ratio, such as standardized mortality ratio (SMR) or standardized incidence ratio (SIR), which are used in cohort studies if the unexposed reference group is the general population, is also a measure of relative risk as is the odds ratio (OR), which is derived from case-control studies.

The interest of risk assessment is usually in excess risk, i.e., the risk attributable to the exposure of interest (risk in the exposed group minus risk in the unexposed group), which is usually not directly estimable from epidemiological studies. The relative risks derived from the epidemiological study or set of studies have to be transformed into excess (lifetime) risk, preferably by means of the life table method (see step 3 described below).

\subsection{Exposure metrics in epidemiological analyses}

Most exposures that are relevant for cancer, as well as for many other chronic diseases, consist of two components, i.e., the level (intensity) of exposure and the duration or frequency of exposure.

Yet, specifying a biologically relevant exposure parameter is complex and even if detailed exposure information is available, it is often not clear how to summarize exposure data into a meaningful exposure metric (Smith, 2002). As both intensity and duration may contribute to risk, various combinations of these components are used in epidemiological analyses. In general, studies either use a form of cumulative exposure, in which the duration of exposure is incorporated, or a form of exposure level without duration, e.g., time-weighted average exposure (dose or concentration) or number of peak exposures within a specified time period. More complex parameterizations of an exposure metric that account for effects of intensity and time in a flexible manner, e.g., giving less weight for more recent exposures, have been described in occupational epidemiology but are scarce (Seixas et al., 1993).

The type of exposure employed in a study determines how the association between the exposure and a disease has to be extrapolated to the situation used in risk assessment for the workplace, in which it is assumed that a worker is exposed for 40 years, beginning at age $20,8 \mathrm{~h} /$ day, etc. Table 2 summarizes which fundamentally different exposure definitions can be distinguished and how they can be extrapolated to the situation at the workplace.

Ideally, risk assessors should have available the information based on the regression model relating exposure to relative risk in which level and duration are separate independent terms (situation 1 in Table 2). This is because it is by no means certain that increasing the exposure duration (e.g., with a factor of 2) has the same impact on cancer risk as increasing the exposure level with the same factor. In fact, examples are available that this is not (always) the case (Verhagen et al., 1994; Voorrips et al., 2000). Unfortunately, occupational epidemiological studies are almost never analyzed with exposure level and duration as separate terms in the model.

In situation 2-representing cumulative exposure, often expressed as ppm.year-it is assumed that duration and level of exposure have the same impact. This type of exposure defi-

Table 2

Types of individual exposure metrics and their extrapolation to risk assessment at the workplace

\begin{tabular}{llll}
\hline & Possibilities & Regression model $^{\mathrm{a}}$ & Extrapolation to workplace \\
\hline 1 & Level + Duration & $\beta_{1} \mathrm{X}_{1}+\beta_{2} \mathrm{X}_{2}$ & Fix duration (X2) to 40 years \\
2 & Level $\times$ Duration & $\beta\left(\mathrm{X}_{1} * \mathrm{X}_{2}\right)$ & Fix duration (X2) to 40 years \\
3 & Level; implicit continuous exposure & $\beta_{1} \mathrm{X}_{1}$ & Duration is (implicitly) the same for each person, therefore level is sufficient \\
4 & Level; no individual duration available & $\beta_{1} \mathrm{X}_{1}$ & Impossible to extrapolate, unless average exposure duration for the study \\
& & & population is available or can be assumed \\
5 & Duration & $\beta_{2} \mathrm{X}_{2}$ & Uniform exposure level assumed throughout exposure period \\
\hline
\end{tabular}

a $\beta_{1}$, regression coefficient relating level of exposure to relative risk; $\mathrm{X}_{1}$, level of exposure (e.g., ambient concentration in $\mathrm{mg} / \mathrm{m}^{3}$ ); $\beta_{2}$, regression coefficient relating duration of exposure to relative risk; $\mathbf{X}_{2}$, duration of exposure (years); $\beta$, regression coefficient relating cumulative exposure to relative risk. 
nition is frequently used in occupational epidemiology. It has the disadvantage that the separate impact of level and duration of exposure on cancer risk can not be distinguished as in situation 1. Therefore, using this exposure metric, an implicit assumption is made that the two have the same impact and are interchangeable, e.g., a cumulative exposure of $40 \mathrm{ppm}$ year results from an exposure to $1 \mathrm{ppm}$ during 40 years, but also from an exposure to $40 \mathrm{ppm}$ during one year.

Situation 3 is not directly applicable to occupational epidemiology, since a subject's duration of exposure depends on the start and end of employment and can therefore not assumed to be constant (unless all workers studied were employed in an exposure-associated job from their 20s until retirement). However, in studies on, for example, dietary habits and cancer this is the usual situation.

Situation 4 is an undesirable situation, because an important determinant of cancer risk, i.e., duration of exposure is missing. Studies that have used such exposure assessment (e.g., "exposed versus unexposed") should ideally not be used for quantitative risk assessment, although they might contribute to hazard identification. If some sort of aggregate information on exposure duration is available, for example average employment duration of the workers or if lifetime employment can be assumed, it might be possible however to use the data from such a study.

In situation 5, information on level of exposure throughout time of employment is missing and therefore constant exposure is - often implicitly-assumed. It depends on knowledge about the exposure conditions in the plant in question whether such a study is acceptable for quantitative risk assessment or not.

\section{Derivation of a risk estimate}

The process to arrive at an acceptable risk estimate comprises three distinctive steps. The first step comprises the evaluation and selection of suitable epidemiological studies. The second step is conducted entirely within the epidemiological study (or set of studies) selected and its aim is to derive the best estimate of an exposure-related relative risk (RR) that is to be used for the risk assessment. In the third and last step, the exposure-related RR derived from the epidemiological study (or studies) is used to estimate the excess lifetime risk (ELR) in the population to which the risk assessment applies. Incorporation of uncertainty estimates is an essential part of the process, whereas sensitivity analyses are useful to check the impact of assumptions made. The steps are summarized in Table 3 .

\subsection{Step 1: evaluation and selection of suitable epidemiological studies}

In epidemiology, the aim is usually to evaluate an association between exposure and disease and to derive a best

Table 3

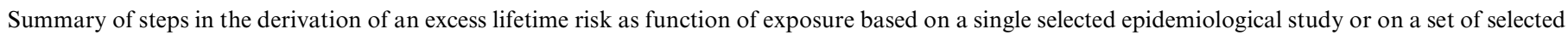
studies

\begin{tabular}{|c|c|c|c|c|}
\hline Step & Aim & Input & Method & Output \\
\hline 1 & $\begin{array}{l}\text { Unbiased selection of } \\
\text { available evidence }\end{array}$ & $\begin{array}{l}\text { All published (peer-reviewed) studies on } \\
\text { the association between the exposure } \\
\text { and outcome of interest (relevant studies) }\end{array}$ & $\begin{array}{l}\text { - Systematic literature search } \\
\text { - Review of all relevant studies for: } \\
\text { - Availability of required data } \\
\text { - Absence of severe flaws }\end{array}$ & $\begin{array}{l}\text { A selection of suitable } \\
\text { studies, meta-analyses and } \\
\text { pooling studies }\end{array}$ \\
\hline 2 & $\begin{array}{l}\text { Establish relative risks (RRs) for } \\
\text { the range of exposure categories } \\
\text { (Study-specific or meta-analysis } \\
\text { or pooling study) }\end{array}$ & $\begin{array}{l}\text { For each exposure category: } \\
\text { - Exposure level } \\
\text { - No. of observed cases and person } \\
\text { years across strata of confounders OR } \\
\text { - No. of observed cases and expected no. of } \\
\text { cases according to reference population } \\
\text { with same confounder distribution OR } \\
\text { - Confounder-adjusted RRs or ORs, or } \\
\text { SMRs/SIRs plus confidence intervals }\end{array}$ & Fit a (regression) model & $\begin{array}{l}\text { A relative risk (RR) } \\
\text { as function of exposure }\end{array}$ \\
\hline \multirow[t]{3}{*}{3} & $\begin{array}{l}\text { Derive an excess lifetime } \\
\text { risk per unit of exposure }\end{array}$ & $\begin{array}{l}\text { - A relative risk (RR) as function } \\
\text { of exposure } \\
\text { AND }\end{array}$ & $\begin{array}{l}\text { 1. Construct life tables for } \\
\text { exposed }^{\mathrm{a}} \text { and unexposed }\end{array}$ & $\begin{array}{l}\text { - An excess lifetime } \\
\text { risk per unit of exposure } \\
\text { ('unit risk') }\end{array}$ \\
\hline & $\begin{array}{l}\text { Derive an excess lifetime } \\
\text { risk for exposed population }\end{array}$ & $\begin{array}{l}\text { Exposure distribution in the } \\
\text { target population } \\
\text { AND }\end{array}$ & $\begin{array}{l}\text { 2. Subtract risk in unexposed from } \\
\text { that in exposed }{ }^{\text {a }} \text { population as } \\
\text { calculated from life tables }\end{array}$ & $\begin{array}{l}\text { - An excess lifetime risk } \\
\text { for a population exposed } \\
\text { at a given level }\end{array}$ \\
\hline & $\begin{array}{l}\text { Derive an exposure at a given } \\
\text { level of excess lifetime risk }\end{array}$ & $\begin{array}{l}\text { - Age-specific incidence (mortality) } \\
\text { of the cancer of interest in the unexposed } \\
\text { (target) population } \\
\text { AND } \\
\text { - Total age-specific mortality in the } \\
\text { (target) population }\end{array}$ & & $\begin{array}{l}\text { - Exposure at a given } \\
\text { level of excess lifetime } \\
\text { risk }\end{array}$ \\
\hline
\end{tabular}

\footnotetext{
${ }^{\text {a }}$ For a specified exposure level.
} 
estimate for the size of the association. As results of individual studies may be influenced by chance or particular circumstances, a review of the whole body of available evidence (including "negative" studies) is considered necessary to obtain an unbiased estimate. Studies may be excluded only if they have serious flaws or provide irrelevant data. In quantitative risk estimation based on animal studies, in contrast, it has been usual practice to select the study with the most conservative, although relevant results on the basis of the precautionary principle. Although the precautionary principle could be applied to epidemiological data as well for the purpose of quantitative risk estimation, we can be sure that in the long run such practice systematically overestimates the impact of exposure on disease.

A quality review of the available data is an essential step in the risk assessment process. The assessor must consider whether the supplied data are complete and valid for use in risk assessment. This should be done according to a structured framework to avoid a strong dependency on the quality of individual judgments. Issues with respect to quality of animal studies (Klimisch et al., 1997) and exposure data (Money and Margary, 2002; Tielemans et al., 2002) in the context of regulatory risk assessment have been discussed in the literature. Checklists for evaluating epidemiological data have mainly been published in the context of conducting meta-analyses (Blair et al., 1995; Stroup et al., 2000; Wong and Raabe, 1996), but the evaluation of epidemiological evidence for quantitative risk assessment has also received some attention (Health Effects Institute, 1999; Hertz-Picciotto, 1995; WHO, 2000b).

\subsubsection{Quality of epidemiological evidence}

Only few, mostly recent epidemiological studies are designed and conducted specifically for quantitative risk assessment purposes. Hence, from a pragmatic point of view it is difficult to rigorously apply a framework for quality evaluation, since a rigid approach may result in the exclusion of a large amount of valuable data. Assessors should carefully evaluate flaws in epidemiological studies before dismissing them as useless for risk assessment in advance. This is in line with a 'weight of evidence' approach according to which all epidemiological evidence with at least acceptable quality are used in a risk assessment process. The information from all studies meeting minimum quality requirements is combined with the aim of obtaining a risk estimate with as much precision and validity as possible (Shore, 1995). Such an approach is also compatible with the recognition that studies of varying quality can have a contribution to different components of the risk assessment process, ranging from detailed exposure-response modeling to hazard identification only.

In general, the validity of exposure-response relations produced by epidemiological studies is determined by the control of bias and confounding that may mask or accentuate risks. Moreover, epidemiological results should be informative in that the results produce relative precise risk estimates. Basic elements of a quality review of an epidemiological study includes study design, selection of the population, exposure pattern, diagnostic criteria, length of observation period, adjustment for confounding factors, statistical analysis, and sample size. For a more complete understanding and in depth discussion of these issues, several overviews of quality issues in epidemiology are available (Blair et al., 1995; Health Effects Institute, 1999; HertzPicciotto, 1995; Stroup et al., 2000; WHO, 2000b; Wong and Raabe, 1996).

\subsubsection{A quantitative exposure assessment component}

Epidemiological studies identified as potentially providing valid exposure-response information have to undergo an additional selection process that considers whether or not the exposure assessment component is quantitative. The importance of correctly ranking subjects according to exposure status has become a central focus of research effort over the past decades (Checkoway et al., 1987; Heederik and Attfield, 2000; Kauppinen, 1994; Kromhout et al., 1999; Seixas and Checkoway, 1995; Stewart, 1999). Yet, correctly estimating absolute exposure levels in the study population has been less of an issue (van den Brandt et al., 2002). Researchers have used various ways of grouping subjects with common occupational exposure levels, such as collection of information on job title or the use of job-specific questionnaires combined with expert evaluations. Recently, Semple et al. showed that expert judgments can potentially yield reliable quantitative exposure estimates (Semple et al., 2001). However, in general these approaches do not result in absolute exposure levels and qualitative categories of exposure are then used instead in epidemiological studies. Qualitative estimates of exposure often take the form of high, medium, and low categories without any indication of the actual range of exposures associated with each category. In these circumstances, different studies with the same exposure category definition may be estimating effects at different points on the exposure-response curve (Blair et al., 1995). Hence, the absence of any quantitative information on exposure precludes the extrapolation of epidemiological evidence to other populations and exposure situations.

If quantitative exposure information is not available one has to evaluate whether other databases containing quantitative exposure information can be used. Such an external source has to be linked to the qualitative exposure categories from the epidemiological study. The variable common to both the external exposure database and the epidemiological study that enables the link between exposure levels and health effects is for instance job title or type of tasks performed by the study subjects. Obviously, the appropriateness of this linkage has an impact on the validity of the exposureresponse modeling. The impact of choices with respect to linking databases can be explored by means of sensitivity analyses using different sets of assumptions. The results of sensitivity analyses may show whether (and to what extent) risk estimates diverge under different assumptions. 
Exposure databases may be held by various organizations, including, among others, companies, labor unions, governmental agencies, published literature. Yet, at the same time difficult methodological obstacles confront the effective use of occupational databases and there is justifiable concern regarding the quality of part of the data (Cherrie et al., 2001; Tielemans et al., 2002). As a result of poor documentation a considerable number of exposure measurements conducted in the past are of little use in the exposure assessment of epidemiological studies. Notwithstanding these important limitations, Burstyn and co-workers showed that it was possible to derive quantitative exposure predictions for an epidemiological study among asphalt pavers using pre-existing data of varying quality from different countries in combination with expert judgment (Burstyn et al., 2000; Burstyn and Kromhout, 2002). These authors illustrated that existing databases may indeed represent a huge potential of knowledge on exposure profiles, which can be used in epidemiological risk analyses.

The end result of this step is the identification of all available studies meeting the criteria for the quantitative risk assessment. Depending on the quantity and type of available data and the preference of the risk assessor, they can either be used as separate studies or their results can be combined in a meta-analysis or pooled analysis before proceeding to step 2. Meta-analyses and pooling studies are very useful to summarize results from many studies in a balanced way (i.e., weighting the studies according to their statistical power) and to enhance precision. An excellent example of a meta-analysis that is directly applicable to quantitative risk assessment is the study by Armstrong et al. (2004) on lung risk cancer after exposure to polycyclic aromatic hydrocarbons (PAHs). The authors combined the results of 39 cohorts and calculated a summary relative risk at an exposure to $100 \mu \mathrm{g} / \mathrm{m}^{3}$.year benzo[ $a$ ]pyrene, which was used as an indicator of exposure to PAHs. At the other hand, the risk assessor may also find it useful to consider a few large studies separately, because the differences between the studies and between their effects on the exposureresponse function provide more insight into the robustness of the final estimate. In such cases, pooling of the results can then be conducted at the end of step 3. If data are available as a data set containing the individual data of the study participants, step 2 must be conducted on this data set.

\subsection{Step 2: fitting a model to epidemiological data}

The purpose of this step is to relate the exposure to the rate of disease in the population studied, i.e., establishing an exposure-response association. The exposure may be expressed as e.g., average exposure to a substance, peak exposure, or alternatively, as a cumulative exposure for each unit of person-time of observation (e.g., ppm-year). The simplest form of this association is based on two categories of exposure, i.e., exposed versus unexposed. However, more than one exposure category is strongly preferable because it allows assessment of the consistency and shape of the association. Although it is possible to use multiple exposure categories as such for most purposes of risk estimation, the data are most efficiently used when a mathematical model is fitted to the data, provided the model fits the data well. Such models can have a variety of forms, ranging from linear to a more complex mathematical function. As most epidemiological studies only publish RRs for categories of exposure, the risk assessor has to decide what mathematical function to fit (see text box). Whatever the model used, the end result of this step is always the RR as a function of exposure (Table 3), where the regression coefficient $(\beta)$ is equivalent to the potency of the carcinogen (van Wijngaarden and HertzPicciotto, 2004).

It is possible that in the publication of an epidemiological study the data analysis that is relevant for risk assessment has been done and that the reported relative risks (RRs) or estimated slope (the regression coefficient) can be used directly to go to step 3 and calculate excess lifetime risks. Unfortunately, however, the data analysis is often done in a suboptimal way, in particular in older publications, and sometimes, authors do not report the results as required for risk assessment (Rushton, 2000; van den Brandt et al., 2002). For example, exposure levels may only be described as high and low or exposure categories may be reported as a range without a point estimate, such as a median or (geometric or arithmetic) average. To use published data effectively for quantitative risk assessment, minimum requirements are that for each exposure category is reported: a point estimate of the exposure level, incidence or mortality rates (adjusted for age and preferably other confounders).

From a statistical point of view, it is strongly preferable, however, to use the number of observed cases and person years-at-risk, i.e., the primary data, for each exposure category. These will allow estimation of a regression coefficient weighted for the information density present in each exposure category and of (correct) confidence intervals around this estimate. Number of cases and person years should either be reported across categories of age and other confounders or, alternatively, the expected number of cases should be available, which are calculated from the rates in the reference population with the same distribution of age (and preferably other confounders) as the subjects in each exposure category (e.g., age/gender/ race standardized). Alternatively, adjusted RRs or SMRs, together with their confidence intervals as reported in a publication can be used.

Poisson regression is particularly suited to use for published, already categorized data. Other options used to analyze epidemiological studies, such as Cox' regression, are also available if the risk assessor disposes of the dataset with individual data. Crump et al. (2003) compared both regression methods in the same data set and found reasonably comparable results. A calculator- or spreadsheet-based estimation using the linear relative risk model has also been proposed (van Wijngaarden and Hertz-Picciotto, 2004). 
How to choose a mathematical model

If sufficient data are available over a whole range of relevant (including low) exposure levels and these data can be fitted appropriately to a (simple or more complex) mathematical exposure-response model, it is preferable to base the calculation of risk on this mathematical model. The reasons for this are that all available information is being used and the consistency of the estimated exposure-response relation can be checked. A mathematical model is furthermore the best available basis for interpolation and provides a good starting point for extrapolation, provided that extrapolation is not conducted far outside the range of observations.

From the literature it appears that the types of mathematical models used are, however, very diverse. Relative risk and additive risk models are both being used, but many authors have concluded that relative risk models are better suited to epidemiological (cancer) data (Breslow and Day, 1980; Crump et al., 2003; Stayner et al., 1995). The same conclusion was reached based on observations of cancer incidence in laboratory animals (Kuo et al., 2002). The difference between the two types of models is that in the relative risk models the effect of exposure multiplies the background risk, whereas in the additive risk models the effect of exposure adds to the background risk. Within the relative risk type of models, a variety of shapes of the exposure-risk relation can be and has been used, e.g., linear, log-linear (exponential), power, square root, polynomial. The log-linear model, where the RR is modeled on a log-scale, is the conventional model used by epidemiologists by default.

The final model chosen is often guided by the best fit to the data, as seems to be the most logical decision. However, many investigators test only one or a few shapes, often without clear arguments. As a result, risk estimates may vary from study to study without an indication of the validity of the models used. As the available epidemiological data are usually relatively sparse, the fit of a model is a criterion not as clear-cut as one would wish because the differences in fit may be small. For reasons of transparency, comprehensibility, comparability, and ultimately acceptability, we think that the linear relative risk model should be the preferred choice, unless there are good reasons to choose a different model. This model has often been found to give the best or almost best fit on cancer epidemiological data and has the advantages that it is easy to interpret for the majority of investigators that are not comfortable with complex mathematical formulas. Furthermore, it does not need an extra step for extrapolation to exposures lower than the observed range, if needed. A limitation of the linear relative risk model is that currently no accepted method is available to pool data from separate studies in a meta-analysis (Armstrong et al., 2004). Steenland and Deddens (2004) suggested a feasible strategy to decide for a model: in a first exploration, a nonor semi-parametric model, such as a regression spline (Durrleman and Simon, 1989), gives a visual evaluation of the shape of the exposure-risk relation. Then, based on this shape, a parametric model is fitted to calculate the risk estimate.

In today's risk assessment, two different paradigms for the shape of a dose-response relationship are being used, based on biological grounds: for genotoxic carcinogens for which a linear shape (without threshold) is assumed, while for all other effects a threshold is assumed to exist below which effects are not expected to occur. It is more and more recognized, however, that a more flexible approach is desirable, in particular if more data on mode of action are available (U.S. Environmental Protection Agency, 2005). Animal studies are usually conducted with very high exposures, requiring extrapolation of the curve at much lower exposures to mimic the exposure situation in man. However, when epidemiological data are used, it makes more sense to "let the data speak for themselves" and therefore not to force a theoretical construct into the exposure-risk function.

\subsection{Step 3: converting the $R R$ to an ELR as function of exposure in the target population}

Two different methods may be applied to calculate the Excess Lifetime Risk (ELR) in the target population from the estimated RR. Some risk assessors use the more simple approach of the cumulative risk (more accurately called "incidence or mortality proportion"), which can be calculated from the incidence (or disease-specific mortality) rate (Rothman and Greenland, 1998). In the simple approach, the excess cumulative risk for one or more exposure levels is calculated from $E L R=R R \times P-P$, in which $\mathrm{P}$ represents the cumulative (lifetime) risk in the non-exposed target population. The state-of-the-art approach is the ELR as calculated from a life table. Both the life table risk and the cumulative risk represent the probability of a disease (or death attributed to a disease) during lifetime or up to a certain age (e.g., 75 years). However, the cumulative risk is a measure conditional upon survival, whereas the life table risk is an unconditional and therefore more accurate estimate of lifetime risk. In contrast to the conditional cumulative risk, the life table risk takes into account that a cohort is dying out from 
other causes of death than the disease under study. The difference in results between the two methods is illustrated in Fig. 1, which demonstrates that overestimation through the conditional cumulative risk becomes larger with increasing old age, when all-cause mortality has a strong impact. It is therefore unnecessarily conservative. The discrepancy will be even larger if mortality due to the effect of the exposure of interest on other causes of death is high. Since calculation of life table risk is straightforward and available (e.g., Steenland et al., 1998), this is the preferred method and is therefore presented as the only possible approach in many reports (e.g., Canadian Environmental Protection Act, 2000; Stayner et al., 1995, 2000; Thomas et al., 1992). Nevertheless, life table risk can be replaced by conditional risk if the background rate of the disease and the potency of the substance are low or if the age for which the risk is considered relevant is relatively young ( $<70$ years).

The life table approach described below is an adaptation of the description in van den Brandt et al. (2002). Besides a $\mathrm{RR}$ as function of exposure, several pieces of information are needed to calculate the ELR as function of exposure with the help of a life table. These pieces are:

- The background rate of the disease or outcome of interest in each age group in the general population. We assume that death is the outcome of interest, but slight modifications can be applied to conduct these calculations for disease incidence.

- The background all-cause mortality rate in each age group in the general population. These should be gender-specific, if the exposure distribution or the relative risks from the published study differ by gender.

- Depending on the purpose of the risk assessment, a distribution or level of exposure in the target population has to be chosen.

A life table is constructed for each level of exposure of interest. In the construction of the table, the measure of exposure must match the one used in the epidemiological study (e.g., ppm-year), see also Table 2. The life table begins at birth or at the age of first occupational exposure, starting with a fixed cohort of a certain size, which is affected at every subsequent age by the mortality and disease rates for that age. The life table continues such that the final interval ends at either a near maximum lifetime (say 90 years) or somewhere near a mean or median lifetime; the current life expectancy for Dutch men is 60 years from age 20 (CBS Statistics Netherlands, 2005). The lifetime risk for an exposed population is derived by applying the RR that was derived from the epidemiological data (step 2) for that level of exposure to the 'background' incidence or mortality rates in the general (unexposed) population at each age. Here again, it is essential that the exposure-risk relation used in the life table is the same as that used in step 2. For example, if the relative risk (RR) for a certain exposure level was 2 in the study, then the rates at each age are multiplied by 2 . These new 'predicted' incidence or mortality rates are used to construct the life table for the exposed population. The cumulative risk through the last age interval is calculated for the given exposure level, and compared to the cumulative risk up to the same achieved lifetime for the unexposed population. The difference is the ELR (Table 3). An example of a life table is presented for the case of hexavalent chromium in the next section.

The description above assumes that the influence of the exposure of interest on the incidence and mortality rates in the general population is negligible. This will be the case for most occupational exposures as the proportion of exposed people among the general population will be very low and also for novel substances to which the population at large has not yet been exposed. Slight adaptations to the method are needed if (part of) the general population has been exposed to the substance of interest (Hertz-Picciotto and $\mathrm{Hu}, 1994$; Korte et al., 2000). If the exposure of interest also causes other deaths than those due to the disease of interest, the calculation should be adapted accordingly.

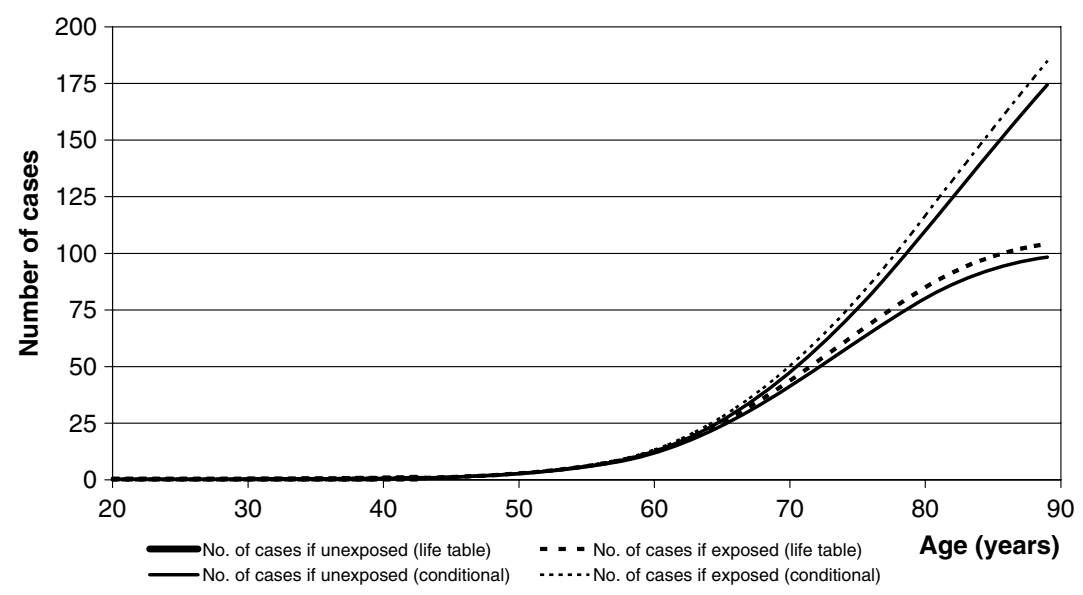

Fig. 1. Lifetime risk of lung cancer in a cohort of 1000 Dutch men, based on mortality rates in 1997 (Visser et al., 2001) according to the life table method and the conditional method. Assumed exposure to an ambient concentration of $1 \mu \mathrm{g} / \mathrm{m}^{3}$ at work from age 20 to 60 and an exposure-risk relation based on a RR of 2.5 for a cumulative exposure to $1 \mathrm{mg} / \mathrm{m}^{3}$.year. The differences between the exposed and unexposed curves represent the ELRs at each age. 
The result obtained from the life table analysis is an ELR as function of exposure, in other words, an ELR for one or (preferably) more levels of exposure or a continuous function with a certain shape. These results can be used further to compare to given exposure scenarios, to derive an exposure level for a given level of excess risk, or to derive an excess risk per unit of exposure. If the shape of the function is non-linear, it can be decided to conduct a linear extrapolation from a certain exposure or excess risk level towards the origin. For example, the US EPA establishes an effective dose (ED), which is the level of exposure associated with a specified level of excess risk in the range of observations (e.g., 10, 1, or 0.1\%) (U.S. Environmental Protection Agency, 2005). Through linear extrapolation, i.e., by connecting the observed ED with the origin (no exposure/no excess risk), the risk per unit of exposure can be derived (e.g., Stayner et al., 2000). In general, the risk assessor has to decide from which point in the curve such extrapolation has to be carried out.

\subsection{Incorporating uncertainty and variability}

As in quantitative risk assessment based on animal studies, estimating the amount of uncertainty is an essential part of the assessment. Although uncertainty is less due to lack of the interspecies extrapolation step and a (usually) less extreme high to low dose extrapolation, other sources of uncertainty inherent in epidemiological studies may be larger than in animal studies. Uncertainty is associated with all steps in the estimation process. Stayner et al. (1999a) studied and listed several sources of uncertainty that are particularly relevant in epidemiological studies: those associated with (1) study design (i.e., small sample size, confounding, other biases, insufficient follow-up), (2) choice of the data set, (3) specification of the dose-response model, (4) estimation of exposure and dose, and (5) unrecognized variability in human susceptibility. It should be noted, however, that some of these sources, such as small sample size, choice of the data, specification of the dose-response model and human variability, equally apply to risk assessment based on animal data.

The degree of uncertainty associated with specific study data is usually described by the $(95 \%)$ confidence interval around the point estimate. The former EPA guidelines prescribed the use of the upper confidence limit (UCL) instead of the point estimate to take into account a worst-case situation (U.S. Environmental Protection Agency, 1986). Alternatively, a probabilistic approach could be used, which can also deal with other sources of uncertainty simultaneously (Steenland and Greenland, 2004; U.S. Environmental Protection Agency, 2005). Although usually more labor-intensive, a probabilistic approach produces more realistic (instead of cumulated worst-case) estimates and a better and more useful characterization of uncertainty. Other potential sources of uncertainty in epidemiological studies, such as bias (for example, the healthy worker effect), exposure measurement error or possible confounding can be estimated, for example in validation studies or, if such studies are not available, from the literature or available knowledge. For example, Steenland and Greenland (2004) showed how the impact of confounding due to smoking could be estimated in a study on exposure to silica and lung cancer, despite the lack of data on smoking in the study subjects. For this study, they showed that the unadjusted SMR of the exposed workers shifted from 1.60 (95\% CI: $1.31-1.93)$ to 1.43 (95\% CI: $1.15-1.78)$ for the smoking-adjusted SMR by applying Monte Carlo sensitivity analysis (a probabilistic approach) using generally available information on prevalence of smoking in blue collar workers and on the effect of smoking on lung cancer risk. Strikingly, this approach introduced only minimal increase in uncertainty, as can be derived from the confidence intervals. Exposure-measurement error correction can also be applied to get a handle on uncertainties connected with exposure assessment in the epidemiological study. For example, in studies on dietary habits and cancer, this is being more and more applied, as demonstrated in a study on meat consumption and large-bowel cancer, in which, besides the exposure data collected via questionnaire in the entire study population, more accurate exposure data were available in an $8 \%$ random sample of the study population (Norat et al., 2005). In this study, the uncorrected RR for large-bowel cancer was 1.25 (95\% CI: $1.09-1.41)$ for every $100 \mathrm{~g}$ meat consumption, whereas the corrected RR was $1.55(95 \%$ CI: 1.19-2.20). Even in absence of a validation study, an estimate of the exposure measurement error can be derived from the literature and incorporated as a source of uncertainty in the risk assessment. Similar work has been done to estimate the possible impact of the healthy worker effect.

\section{Example on chromium}

Hexavalent, but not trivalent, chromium causes cancer in laboratory animals and has been classified as a human carcinogen via inhalation (International Agency for research on Cancer, 1990). Many epidemiological cohort studies on occupational chromium exposure and risk of lung cancer have been published over the last 30 years (International Agency for research on Cancer, 1990). A few of those studies have been used in one or more of the available risk assessments for chromium (Dutch Expert Committee on Occupational Standards, 1998; European Union Risk Assessment Report, 2002; Scientific Committee on Occupational Exposure Limits, 2003; Sorahan et al., 1998b; U.S. Environmental Protection Agency, 1998; WHO, 2000a). It was not always clear from the reports why the studies were selected, but important reasons were the size of the studies and the availability of multiple quantitative exposure categories. More recently, new studies on existing cohorts have been published, which are very suitable for quantitative risk estimation (Crump et al., 2003; Gibb et al., 2000). 


\subsection{Step 1: selection of studies}

As the chromium example is used specifically to illustrate and discuss the principles of and approach for derivation of quantitative risk estimates from epidemiological data (i.e., steps 2 and 3), we skipped the formal quality review of the studies and included the studies that were used in previous quantitative risk assessments in addition to the two recent studies. A summary of those cohorts is presented in Table 4. From more than one publication of the same cohort, the last publication with the latest update of follow-up in the cohort was used.

The three studies by Mancuso (1997), Gibb et al. (2000), and Crump et al. (2003) appeared to be the only studies with quantitative exposure estimates and both studies used more than one exposure category. The study by Mancuso et al. was used in the risk assessment conducted by the EPA (U.S. Environmental Protection Agency, 1998) as the best study before the much larger study by Gibb et al. became available. The study by Sorahan et al. (1998a), a qualitatively acceptable study in which the level of exposure to chromium was not available, was nevertheless used to conduct a quantitative risk assessment by postulating a posteriori a range of exposure levels (Sorahan et al., 1998b). The meta-analysis by Steenland et al. (1996), based on 10 occupationally exposed chromium cohorts, did not have quantitative exposure estimates either, but was used in the risk assessment conducted by the EU Scientific Committee for Occupational Exposure Limits using the same approach as Sorahan et al. assuming several exposure levels (Scientific Committee on Occupational Exposure Limits, 2003). The purpose of the publication by Crump et al. (2003) was quantitative risk estimation.

We selected the three cohort studies by Mancuso (1997), Gibb et al. (2000), and Crump et al. (2003) for quantitative risk estimation. All three publications report the minimally required data, have quantified exposure (based on airborne concentrations of chromium), and used several exposure categories to enable exposure-response modeling (Table 4).

The Mancuso study is the smallest and exposure assessment was based on one industrial hygiene survey only. However, exposure levels and contrast in exposure were high. No information on smoking status of the cohort was available. The Gibb study was by far the largest study, exposure assessment was based on frequent industrial hygiene surveys, and data on smoking status were available for $93 \%$ of the cohort, which is important, as smoking is a strong determinant of lung cancer and therefore a serious potential confounder. The exposure levels and contrast in exposure were, however, low. The Crump study, conducted in cohorts from the same Ohio plants but from a more recent generation than the Mancuso study, was much smaller, but had extensive exposure information and relatively high exposure levels. Smoking status was known for part of the cohort. Besides the data extracted for the purpose of this paper, the authors of one of the original papers also investigated other exposure metrics (peak exposure by Crump et al.). These are not included in the present paper. Furthermore, two studies used cumulative exposure lagged by 5 years (Crump et al., 2003; Gibb et al., 2000). This was done to improve the fit of the model (step 2) and is understandable as clinical cancer develops considerable time after exposure.

Table 4

Selection of occupational studies on chromium exposure and lung cancer risk

\begin{tabular}{|c|c|c|c|c|c|c|c|}
\hline Study type & Reference & Country & $\begin{array}{l}\text { Exposure } \\
\text { period }\end{array}$ & $\begin{array}{l}\text { Follow-up } \\
\text { period }\end{array}$ & Type of data reported & Exposure categories & Exposure assessment \\
\hline $\begin{array}{l}\text { Meta-analysis } \\
\text { of cohorts }\end{array}$ & $\begin{array}{l}\text { Steenland et al. } \\
\text { (1996) }\end{array}$ & Several & Diverse & Diverse & $\begin{array}{l}\text { Mean SMR based on } \\
10 \text { studies }\end{array}$ & $\begin{array}{l}\text { 1; no quantification; } \\
\text { no duration }\end{array}$ & \\
\hline Cohort & $\begin{array}{l}\text { Sorahan et al. } \\
\text { (1998a) }\end{array}$ & $\begin{array}{l}\text { Great Britain } \\
\text { Midlands }\end{array}$ & $1946-1975$ & $1946-1995$ & $\begin{array}{l}\text { No. of cases and expected } \\
\text { no. of cases (standardized } \\
\text { for age, sex, calendar year) }\end{array}$ & $\begin{array}{l}1 ; \text { no quantification; } \\
4 \text { categories of duration }\end{array}$ & \\
\hline Cohort & $\begin{array}{l}\text { Mancuso } \\
(1997)\end{array}$ & USA Ohio & $1931-1937$ & $1931-1993$ & $\begin{array}{l}\text { - Age-adjusted } \\
\text { mortality rates } \\
\text { - No. of cases and } \\
\text { person-years } \\
\text { stratified on age }\end{array}$ & $\begin{array}{l}\text { 6; range per category; } \\
\text { cumulative exposure, } \\
\text { quantified as airborne } \\
\text { soluble Cr conc. }\end{array}$ & $\begin{array}{l}1 \text { industrial hygiene } \\
\text { survey (1949), } \\
\text { combined with } \\
\text { job titles }\end{array}$ \\
\hline Cohort & $\begin{array}{l}\text { Gibb et al. } \\
(2000)\end{array}$ & USA Maryland & $1950-1974$ & $1950-1992$ & $\begin{array}{l}\text { - No. of cases, person-years } \\
\text { and expected no. of cases } \\
\text { stratified on age } \\
\text { - Age- and smoking-adjusted } \\
{\text { regression coefficient }{ }^{\mathrm{a}}}^{\text {regrion }}\end{array}$ & $\begin{array}{l}4 ; \text { mean per category; } \\
\text { cumulative exposure, } \\
\text { quantified as airborne } \\
\mathrm{CrO}_{3} \text { conc. }\end{array}$ & $\begin{array}{l}70,000 \text { contemporary } \\
\text { industrial hygiene } \\
\text { measurements, } \\
\text { combined with } \\
\text { job titles }\end{array}$ \\
\hline Cohort & $\begin{array}{l}\text { Crump et al. } \\
(2003)\end{array}$ & USA Ohio & $1940-1972$ & $1940-1997$ & $\begin{array}{l}\text { - No. of cases, person-years } \\
\text { and expected no. of cases } \\
\text { (standardized for age) } \\
\text { - Age-adjusted regression } \\
\text { coefficient }^{\text {b }}\end{array}$ & $\begin{array}{l}10 ; \text { mean per category; } \\
\text { cumulative exposure, } \\
\text { quantified as airborne } \\
\text { hexavalent Cr conc. }\end{array}$ & $\begin{array}{l}26 \text { industrial } \\
\text { hygiene surveys } \\
\text { conducted over } \\
\text { time, combined } \\
\text { with job titles }\end{array}$ \\
\hline
\end{tabular}

${ }^{a}$ Regression coefficient $(\beta)$ based on log-linear model and log-transformed cumulative exposure: $\mathrm{RR}=\exp \left(\beta^{10} \log\right.$ [cumulative exposure] $)$.

${ }^{\mathrm{b}}$ Regression coefficient $(\beta)$ based on linear model: $\mathrm{RR}=1+\beta[$ cumulative exposure]. 


\subsection{Step 2: fitting a model to epidemiological data}

The published data from the three selected studies are presented in Table 5. We decided to estimate the lifetime risk of cancer for all three studies separately and not use a combined estimate of the RR to get better insight into the differences and similarities between the estimates. Ultimately, the estimates may be pooled into one estimate.

We used, as did Crump et al., the most straightforward model, i.e., the linear relative risk model $[R R=1+$ $\beta$ (exposure)]. This model can be fitted to the data through Poisson regression, taking into account several forms of availability of the published data. For the Crump data, we replicated and used (almost) the same potency estimate ( $\beta=0.7925)$ as reported by the authors (Crump et al., 2003). As comparison, we also fitted the log-linear model $\left[R R=e^{\beta \text { (exposure) }}\right]$ on the three datasets through Poisson regression. The data we used were those displayed in Table 5; however, for Gibb et al. we used the age-stratified data from the publication (Table $\mathrm{V}$ from the original publication) and for Mancuso we initially used the age-stratified data as well (Table XII from the publication). As the linear Poisson regression model failed to converge for the Mancuso data, we used linear regression (least squares) with the reported age-adjusted lung cancer mortality rates (Table 5) instead. As the Gibb exposure data were based on $\mathrm{CrO}_{3}$ instead of elemental chromium, the exposure data were rescaled to elemental chromium.
The results of the fitted models for each of the data sets are presented in Table 6 . Whereas the predicted relative risk per unit of exposure was twice as large for the Mancuso data compared to the Crump data, the relative risks for the Gibb data were much higher. The results did not differ very much between the linear and log-linear model for the Mancuso and Crump data, in contrast to the Gibb dataset, which resulted in very high RRs for the log-linear model.

\subsection{Step 3: converting the RR to an ELR as function of exposure}

We developed a life table based on Dutch data for lung cancer mortality and all-cause mortality and calculated the ELR from the three studies by using as input the linear relative risk function of cumulative exposure as derived from the Poisson regression. As an example, the abridged life table used for the ELR calculation from the study by Crump et al. is presented in Table 7. The life table risk in Fig. 1 was produced from such a life table.

The ELRs up to age 89 per $1 \mu \mathrm{g} / \mathrm{m}^{3}$ chromium as calculated from the life tables, range between 3 and $16 \times 10^{-3}$ for the three datasets (Table 8). If based on conditional risk up to age 89, the ELRs are almost twice as high. If the background lung cancer mortality in the (target) population would be that of a non-smoking population, the ELRs are 10 times smaller.

Table 5

Summary of data from cohort studies with quantitative exposure data as reported by authors

\begin{tabular}{|c|c|c|c|c|c|c|}
\hline $\begin{array}{l}\text { Cumulative exposure } \\
\text { categories }\left(\mathrm{mg} / \mathrm{m}^{3} \cdot \text { year }\right)\end{array}$ & $\begin{array}{l}\text { Average cumulative } \\
\text { exposure }\left(\mathrm{mg} / \mathrm{m}^{3} \cdot \text { year }\right)\end{array}$ & Person years & $\begin{array}{l}\text { Lung cancer } \\
\text { deaths }\end{array}$ & $\begin{array}{l}\text { Expected no. of } \\
\text { lung cancer deaths }\end{array}$ & $\begin{array}{l}\text { Lungca-rate } \\
\text { age-adjusted }^{\text {a }}\end{array}$ & RR/SMR \\
\hline \multicolumn{6}{|c|}{ Mancuso (1997, Table VI, soluble Cr) } & RR \\
\hline$<0.25$ & $0.125^{\mathrm{b}}$ & 4375 & 5 & na & 99.7 & 1 (reference) \\
\hline $0.25-0.49$ & $0.375^{\mathrm{b}}$ & 1952 & 10 & na & 503.7 & 5.1 \\
\hline $0.50-0.99$ & $0.75^{\mathrm{b}}$ & 2676 & 16 & na & 605.3 & 6.1 \\
\hline $1.00-1.99$ & $1.5^{\mathrm{b}}$ & 2526 & 19 & na & 794.6 & 8.0 \\
\hline $2.00-3.99$ & $3^{\mathrm{b}}$ & 1180 & 14 & na & 1312.8 & 13.2 \\
\hline$\geqslant 4.00$ & $5^{\mathrm{b}}$ & 172 & 2 & na & $(2848.3)$ & $(28.6)$ \\
\hline \multicolumn{6}{|c|}{ Gibb et al. $\left(2000 \text {, Table VI, hexavalent } \mathrm{CrO}_{3}\right)^{\mathrm{c}}$} & SMR \\
\hline $0-0.00149$ & 0.00045 & 28,512 & 26 & 27.1 & na & 0.96 \\
\hline $0.0015-0.0089$ & 0.0042 & 14,879 & 28 & 19.8 & na & 1.42 \\
\hline $0.009-0.0769$ & 0.030 & 15,194 & 30 & 19.1 & na & 1.57 \\
\hline $0.077-5.25$ & 0.449 & 13,409 & 38 & 17.0 & na & 2.24 \\
\hline \multicolumn{6}{|c|}{ Crump et al. (2003, Table IV, hexavalent Cr) } & SMR \\
\hline $0.00-0.06$ & 0.00976 & 3112 & 0 & 2.09 & na & 0 \\
\hline $0.06-0.18$ & 0.115 & 1546 & 3 & 2.19 & na & 1.4 \\
\hline $0.18-0.30$ & 0.233 & 1031 & 3 & 2.19 & na & 1.4 \\
\hline $0.30-0.46$ & 0.386 & 1130 & 5 & 2.13 & na & 2.3 \\
\hline $0.46-0.67$ & 0.563 & 1257 & 0 & 2.20 & na & 0 \\
\hline $0.67-1.00$ & 0.817 & 1431 & 4 & 2.22 & na & 1.8 \\
\hline $1.00-1.63$ & 1.27 & 1493 & 12 & 2.23 & na & 5.4 \\
\hline $1.63-2.60$ & 2.09 & 1291 & 3 & 2.18 & na & 1.4 \\
\hline $2.60-4.45$ & 3.37 & 1248 & 10 & 2.18 & na & 4.6 \\
\hline $4.45-29.0$ & 7.55 & 904 & 11 & 2.12 & na & 5.2 \\
\hline
\end{tabular}

na, not available.

a No. of cases per 100,000 person years.

b Midpoint of category.

c $1 \mathrm{mg} \mathrm{CrO} \sim 0.5 \mathrm{mg}$ hexavalent $\mathrm{Cr}$. 
Table 6

Relative risks (RRs) for lung cancer death for different exposure levels predicted from log-linear and linear models (Poisson regression)

\begin{tabular}{|c|c|c|c|c|c|c|}
\hline \multirow{2}{*}{$\begin{array}{l}\text { Cumulative exposure to } \\
\mathrm{Cr}^{\mathrm{VI}}\left(\mathrm{mg} / \mathrm{m}^{3} \text { year }\right)\end{array}$} & \multicolumn{2}{|c|}{ Mancuso (1997) } & \multicolumn{2}{|c|}{ Gibb et al. (2000) } & \multicolumn{2}{|c|}{ Crump et al. (2003) } \\
\hline & Log-linear ${ }^{\mathrm{a}}$ & Linear $^{\mathrm{b}, \mathrm{c}}$ & Log-linear ${ }^{\mathrm{a}}$ & Linear $^{\mathrm{b}}$ & Log-linear ${ }^{\mathrm{a}}$ & Linear $^{\mathrm{b}}$ \\
\hline 0 & 1 & 1 & 1 & 1 & 1 & 1 \\
\hline 1 & 1.6 & 2.5 & 7.0 & 5.3 & 1.3 & 1.8 \\
\hline 2 & 2.5 & 4.1 & 49.1 & 9.5 & 1.7 & 2.6 \\
\hline 3 & 4.0 & 5.6 & 344.2 & 13.8 & 2.1 & 3.4 \\
\hline 4 & 6.4 & 7.1 & 2412.4 & 18.1 & 2.8 & 4.2 \\
\hline 5 & 10.2 & 8.6 & $16,907.3$ & 22.4 & 3.6 & 5.0 \\
\hline
\end{tabular}

a $\mathrm{RR}=\mathrm{e}^{\beta(\text { exposure })}$

b $\mathrm{RR}=1+\beta$ (exposure).

c As the Poisson regression model failed to converge, least square linear regression was applied to the age-adjusted rates, with exclusion of the highest exposure level due to small number of cases.

Table 7

Life table calculation of the excess lifetime (i.e., until age 89) risk for lung cancer death due to hexavalent chromium exposure in Dutch workers

\begin{tabular}{|c|c|c|c|c|c|c|c|c|c|c|c|c|}
\hline \multirow{2}{*}{$\begin{array}{l}\text { Exact } \\
\text { age }^{\text {a }}\end{array}$} & \multirow{2}{*}{$\begin{array}{l}\text { Cohort } \\
\text { at risk }\end{array}$} & \multicolumn{2}{|c|}{ Exposure } & \multirow{2}{*}{$\begin{array}{l}\text { Prob. of } \\
\text { death }^{\mathrm{e}}\end{array}$} & \multirow{2}{*}{$\begin{array}{l}\text { No.of } \\
\text { deaths }^{f}\end{array}$} & \multicolumn{3}{|c|}{ Among unexposed } & \multirow[t]{2}{*}{$\mathrm{RR}^{\mathrm{i}}$} & \multicolumn{3}{|c|}{ Among exposed } \\
\hline & & Level $^{\mathrm{c}}$ & Cumulative $^{\mathrm{d}}$ & & & $\begin{array}{l}\text { Lung cancer } \\
\text { death rate }\end{array}$ & $\begin{array}{l}\text { Cases } \\
\text { expected }^{\mathrm{h}}\end{array}$ & $\begin{array}{l}\text { Cum cases } \\
\text { expected }^{\mathrm{h}}\end{array}$ & & $\begin{array}{l}\text { Cases } \\
\text { predicted }^{\mathrm{j}}\end{array}$ & $\begin{array}{l}\text { Cum cases } \\
\text { predicted }^{\mathrm{j}}\end{array}$ & $\begin{array}{l}\text { Excess } \\
\text { risk }^{\mathrm{k}}\end{array}$ \\
\hline 20 & 1000 & 0.001 & 0 & 0.0007 & 0.70 & 0.06 & 0.00 & 0.00 & 1.00 & 0.00 & 0.00 & 0.00 \\
\hline 21 & 999 & 0.001 & 0.001 & 0.0007 & 0.70 & 0.08 & 0.00 & 0.00 & 1.00 & 0.00 & 0.00 & 0.00 \\
\hline 22 & 999 & 0.001 & 0.002 & 0.0005 & 0.50 & 0.12 & 0.00 & 0.00 & 1.00 & 0.00 & 0.00 & 0.00 \\
\hline 23 & 998 & 0.001 & 0.003 & 0.0007 & 0.70 & 0.16 & 0.00 & 0.00 & 1.00 & 0.00 & 0.00 & 0.00 \\
\hline 24 & 997 & 0.001 & 0.004 & 0.0007 & 0.70 & 0.22 & 0.00 & 0.01 & 1.00 & 0.00 & 0.01 & 0.00 \\
\hline 25 & 997 & 0.001 & 0.005 & 0.0009 & 0.90 & 0.29 & 0.00 & 0.01 & 1.00 & 0.00 & 0.01 & 0.00 \\
\hline 26 & 996 & 0.001 & 0.006 & 0.0007 & 0.70 & 0.39 & 0.00 & 0.01 & 1.00 & 0.00 & 0.01 & 0.00 \\
\hline 27 & 995 & 0.001 & 0.007 & 0.0006 & 0.60 & 0.51 & 0.01 & 0.02 & 1.01 & 0.01 & 0.02 & 0.00 \\
\hline 28 & 995 & 0.001 & 0.008 & 0.0007 & 0.70 & 0.66 & 0.01 & 0.02 & 1.01 & 0.01 & 0.02 & 0.00 \\
\hline 29 & 994 & 0.001 & 0.009 & 0.0006 & 0.60 & 0.85 & 0.01 & 0.03 & 1.01 & 0.01 & 0.03 & 0.00 \\
\hline 30 & 993 & 0.001 & 0.010 & 0.0007 & 0.70 & 1.08 & 0.01 & 0.04 & 1.01 & 0.01 & 0.04 & 0.00 \\
\hline 31 & 993 & 0.001 & 0.011 & 0.0008 & 0.79 & 1.36 & 0.01 & 0.06 & 1.01 & 0.01 & 0.06 & 0.00 \\
\hline 58 & 921 & 0.001 & 0.038 & 0.0086 & 7.92 & 121.65 & 1.12 & 8.72 & 1.03 & 1.15 & 8.94 & 0.22 \\
\hline 59 & 913 & 0.001 & 0.039 & 0.0093 & 8.49 & 153.52 & 1.40 & 10.12 & 1.03 & 1.45 & 10.38 & 0.26 \\
\hline 60 & 905 & 0.001 & 0.04 & 0.0105 & 9.50 & 185.39 & 1.68 & 11.79 & 1.03 & 1.73 & 12.11 & 0.32 \\
\hline 61 & 895 & 0 & 0.04 & 0.0121 & 10.83 & 217.26 & 1.94 & 13.74 & 1.03 & 2.01 & 14.12 & 0.38 \\
\hline 62 & 884 & 0 & 0.04 & 0.0133 & 11.76 & 249.13 & 2.20 & 15.94 & 1.03 & 2.27 & 16.39 & 0.45 \\
\hline 63 & 872 & 0 & 0.04 & 0.0147 & 12.82 & 281.00 & 2.45 & 18.39 & 1.03 & 2.53 & 18.92 & 0.53 \\
\hline 64 & 859 & 0 & 0.04 & 0.0165 & 14.18 & 312.87 & 2.69 & 21.08 & 1.03 & 2.77 & 21.69 & 0.61 \\
\hline 82 & 349 & 0 & 0.04 & 0.1087 & 37.93 & 834.00 & 2.91 & 86.40 & 1.03 & 3.00 & 89.08 & 2.68 \\
\hline 83 & 311 & 0 & 0.04 & 0.1194 & 37.13 & 834.00 & 2.59 & 89.00 & 1.03 & 2.68 & 91.76 & 2.76 \\
\hline 84 & 274 & 0 & 0.04 & 0.1342 & 36.74 & 834.00 & 2.28 & 91.28 & 1.03 & 2.36 & 94.12 & 2.84 \\
\hline 85 & 237 & 0 & 0.04 & 0.1475 & 34.95 & 834.00 & 1.98 & 93.25 & 1.03 & 2.04 & 96.15 & 2.90 \\
\hline 86 & 202 & 0 & 0.04 & 0.1514 & 30.57 & 834.00 & 1.68 & 94.94 & 1.03 & 1.74 & 97.89 & 2.95 \\
\hline 87 & 171 & 0 & 0.04 & 0.1749 & 29.96 & 834.00 & 1.43 & 96.37 & 1.03 & 1.47 & 99.37 & 3.00 \\
\hline 88 & 141 & 0 & 0.04 & 0.1975 & 27.91 & 834.00 & 1.18 & 97.55 & 1.03 & 1.22 & 100.58 & 3.04 \\
\hline 89 & 113 & 0 & 0.04 & 0.2163 & 24.52 & 834.00 & 0.95 & 98.49 & 1.03 & 0.98 & 101.56 & 3.07 \\
\hline
\end{tabular}

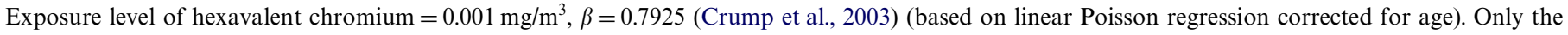
start, the middle part and the end of the life table are reproduced.

a $20=20$ years 0 days.

b Population at risk at exact age.

c Average ambient exposure at the workplace $\left(\mathrm{mg} / \mathrm{m}^{3}\right)$.

d Cumulative exposure at exact age $\left(\mathrm{mg} / \mathrm{m}^{3} \cdot\right.$ year $)$.

e Probability of death before next birthday (CBS1997).

f Number of deaths occuring at that age, in the absence of any exposure effect.

g Death rate from lung cancer in general male population (per 100,000, Visser et al., 2001).

$\mathrm{h}$ (Cumulative) expected number of deaths from lung cancer in absence of any exposure effect.

${ }^{\mathrm{i}} \mathrm{RR}=1+\beta$ (cumulative exposure), according to linear relative risk model.

$\mathrm{j}$ (Cumulative) predicted number of lung cancer deaths.

k Excess number of lung cancer deaths up to that age. 
Table 8

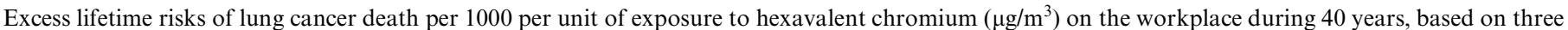
different datasets and the linear relative risk model

\begin{tabular}{|c|c|c|c|}
\hline Data set & Mancuso (1997) & Gibb et al. (2000) & Crump et al. (2003) \\
\hline \multicolumn{4}{|l|}{ Life table method } \\
\hline Up to age 74 & 3.4 & 9.4 & 1.8 \\
\hline Up to age $80^{\mathrm{a}}$ & 4.8 & 13.3 & 2.5 \\
\hline Up to age 89 & 5.9 & 16.4 & 3.0 \\
\hline \multicolumn{4}{|l|}{ Conditional method } \\
\hline Up to age 74 & 4.2 & 11.8 & 2.1 \\
\hline Up to age $80^{\mathrm{a}}$ & 6.6 & 18.7 & 3.3 \\
\hline Up to age 89 & 10.5 & 29.7 & 5.2 \\
\hline Low background lung cancer mortality risk ${ }^{b}$ & 0.6 & 1.7 & 0.3 \\
\hline
\end{tabular}

a Current life expectancy from birth of Dutch men who survived up to age 20 .

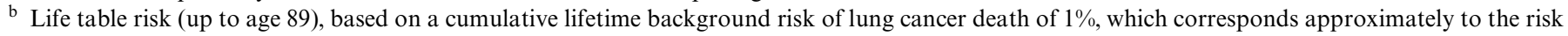
in a population of never smokers.

\section{Discussion}

Since the purpose of our paper was not to establish the best quantitative estimate of lung cancer risk attributed to exposure to hexavalent chromium, but rather to give insight into the type of data and procedures required to derive such estimates from epidemiological studies, we simplified some of the choices made. For example, we did not review all available studies and did not include all eligible studies of sufficient quality, as is required for a proper weight-of-evidence approach. Nevertheless, the three relatively large studies with exposure information available were included. Also, from the multitude of possibilities to fit a mathematical (or biological) model to the exposureresponse data, we choose the two most simple and straightforward to interpret, i.e., the linear and log-linear relative risk model. Many of the other quantitative risk estimations of chromium were based on a variety of models, e.g., Canadian Environmental Protection Act, which used a timeweighted quadratic additive risk model (Canadian Environmental Protection Act, 1994) or US EPA, which used the multistage (biological) model (U.S. Environmental Protection Agency, 1998). We also used cumulative exposure as exposure metric, as this was the metric available for all three studies and it is certainly one of the most frequently used exposure metrics in occupational epidemiology. This does not, however, imply that other exposure metrics may not be relevant. Last but not least we did not attempt to include any uncertainty estimates in the example.

The results (point estimates) of the risk estimation based on the three studies (linear relative risk model) were all within a relatively small range, i.e., $3-16 \times 10^{-3}$ excess lung cancer deaths up to age 89 . The Gibb study resulted in the highest estimates, because it had the steepest slope; the difference between this and the other two studies was that the average exposure was lower and the exposure range much smaller in the Gibb study. This might indicate that the true shape of the exposure-response relation is more like square root, where the curve begins steep but levels off at higher exposures. Such a shape has been observed for many other substances as well, but it is speculated that it is due to bias (Stayner et al., 2003). On the other hand, it might reflect that the Gibb study, although by far the largest, is hampered by the small range of exposure resulting in a less robust estimate of the slope, due to a low signal-tonoise ratio. The results from the Gibb study also clearly demonstrate the danger of extrapolating from a fitted model outside the range of observation: in the log-linear model the RRs are unrealistically high at higher exposure levels, but it should be realized that these RRs are not based on actual observations, but purely on extrapolation. The log-linear is model is the model normally used in epidemiology, but the majority of epidemiologists is not interested in extrapolation outside the range of observations. For risk assessment, however, where prediction of risks at exposure levels lower or higher than those observed in the underlying studies can be the primary aim, the choice of the model is much more critical than in conventional epidemiology. As the log-linear relative risk model is particularly susceptible to overestimation of risk at the right side of the exposure range in the data, for example when a risk estimate is calculated for a worst-case exposure scenario, it is important for further evolution of quantitative risk assessment based on epidemiological studies that statistical methods are developed to conduct a meta-analysis using the linear relative risk model.

The example illustrated that the outcome of the risk assessment process as quantified by the ELR relies heavily on the background rates of specific cancers in the population of interest, since relative risk is used as input. If this background rate is strongly influenced by other environmental or lifestyle risk factors, such as smoking on lung cancer, the derived excess lifetime risk may vary with a factor of up to 10 depending on the proportion of smokers in the population. This is true even if the epidemiological data may have shown that no interaction between the two risk factors was present. In other words, the RR for exposure to a certain substance can be the same for smokers as for nonsmokers, but the ELR shows a difference up to one order of magnitude depending on the proportion of smokers in the population. This is because the effect of exposure multiplies the background risk in relative risk models. Several solu- 
tions are possible to this problem, but all solutions have in common that, in the underlying study, information on the distribution of this other risk factor and, preferably, on the combined effect of the two risk factors should be available.

Other quantitative risk assessments for the worker population obtained the following ELRs per unit of cumulative exposure to $\mathrm{Cr}^{\mathrm{VI}}\left(1 \mu \mathrm{g} / \mathrm{m}^{3}\right.$. year). Based on the early study by Mancuso (1975), US EPA (U.S. Environmental Protection Agency, 1998) calculated an ELR (life table risk up to age 74 ) of $11.6 \times 10^{-3}$ for the general population assuming continuous, lifetime exposure, using the multistage model. Recalculation for the (not-continuously) exposed worker population results in an ELR of $1.3 \times 10^{-3}$. Sorahan et al. (1998b) found a range of ELRs (for life table risk up to age 85) between 0.3 and $8.1 \times 10^{-3}$, based on a British cohort (see Table 4) (Sorahan et al., 1998a) using the linear relative risk model. The authors conducted a sensitivity analysis using a range of hypothesized exposure levels and also incorporating several levels of bias in the results of the epidemiological study. The Scientific Committee on Occupational Exposure Limits of the European Union (Scientific Committee on Occupational Exposure Limits, 2003) derived lower ELRs of $0.1-0.6 \times 10^{-3}$ (for life table risk up to age 85 ), based on a meta-analysis of 10 cohort studies (see Table 4) (Steenland et al., 1996). As no data on duration of exposure were available in the meta-analysis (situation 4 in Table 2), the risk assessors assumed an average individual exposure duration of 15 years. The authors conducted a sensitivity analysis similar to Sorahan et al. (1998b), but with higher hypothesized ambient exposure levels, resulting in lower ELR estimates per unit of exposure. The World Health Organization (WHO, 2000b) used the study by Hayes et al. (1979) in combination with that by Braver et al. (1985) for the exposure assessment and another study by Langard et al. (1990) for derivation of ELRs. Conditional ELRs between $1.3 \times 10^{-1}$ and $4.3 \times 10^{-2}$ were calculated for continuous, lifetime exposure of the general population, using the linear relative risk model. Given the available, but scattered risk assessments for hexavalent chromium and lung cancer, a new assessment, following the proposed scheme, might be useful, not only to establish a 'weight-of-the-evidence' risk estimate, but also to identify better the sources of variation in the ELR estimate among the studies and methods used.

In conclusion, we described a framework to conduct quantitative risk assessment based on epidemiological studies in a structured, transparent and reproducible manner. Important features of the process include a weight-of-theevidence approach, estimation of the optimal exposure-risk function by fitting a regression model to the epidemiological data, estimation of uncertainty introduced by potential biases and missing information in the epidemiological studies, and calculation of excess lifetime risk through a life table to take into account competing risks. Sensitivity analyses are a useful tool to obtain insight into the impact of assumptions made and the variability of the underlying data. The framework is sufficiently flexible to allow many types of data, including published, sometimes incomplete data, but also more complex detailed individual exposure data, while maintaining an optimal result, i.e., a state-ofthe-art risk estimate with confidence intervals, based on all available evidence of sufficient quality.

\section{References}

Armstrong, B., Hutchinson, E., Unwin, J., Fletcher, T., 2004. Lung cancer risk after exposure to polycyclic aromatic hydrocarbons: a review and meta-analysis. Environ. Health Perspect. 112, 970-978.

Blair, A., Burg, J., Foran, J., Gibb, H., Greenland, S., Morris, R., Raabe, G., Savitz, D., Teta, J., Wartenberg, D., 1995. Guidelines for application of meta-analysis in environmental epidemiology. Regul. Toxicol. Pharmacol. 22, 189-197.

Braver, E.R., Infante, P., Chu, K., 1985. An analysis of lung cancer risk from exposure to hexavalent chromium. Teratog. Carcinog. Mutagen 5, 365-378.

Breslow, N.E., Day, N.E., 1980. Statistical methods in cancer research. Volume I-The analysis of case-control studies. IARC Sci. Publ. 5-338.

Burstyn, I., Kromhout, H., Kauppinen, T., Heikkila, P., Boffetta, P., 2000. Statistical modelling of the determinants of historical exposure to bitumen and polycyclic aromatic hydrocarbons among paving workers. Ann. Occup. Hyg. 44, 43-56.

Burstyn, I., Kromhout, H., 2002. The Babel of multicenter exposure assessment. Ann. Occup. Hyg. 46, 649-652.

Canadian Environmental Protection Act, 2000. Priority substances list assessment report. 1,3-Butadiene.

Canadian Environmental Protection Act, 1994. Priority substances list assessment report. Chromium and its compounds.

CBS Statistics Netherlands, 2005. Key features of the population forecast. $<$ http://statline.cbs.nl>

Checkoway, H., Dement, J.M., Fowler, D.P., Harris Jr., R.L., Lamm, S.H., Smith, T.J., 1987. Industrial hygiene involvement in occupational epidemiology. Am. Ind. Hyg. Assoc. J. 48, 515-523.

Cherrie, J.W., Kromhout, H., Semple, S., 2001. The importance of reliable exposure estimates in deciding whether trichloroethylene can cause kidney cancer. J. Cancer Res. Clin. Oncol. 127, 400-404.

Crump, C., Crump, K., Hack, E., Luippold, R., Mundt, K., Liebig, E., Panko, J., Paustenbach, D., Proctor, D., 2003. Dose-response and risk assessment of airborne hexavalent chromium and lung cancer mortality. Risk Anal. 23, 1147-1163.

Durrleman, S., Simon, R., 1989. Flexible regression models with cubic splines. Stat. Med. 8, 551-561.

Dutch Expert Committee on Occupational Standards, 1998. Chromium and its inorganic compounds. Publication No. 1998/01 WGD. Health Council of the Netherlands, Rijswijk.

European Union Risk Assessment Report, 2002. Chromium trioxide (CAS No. 1333-82-0), sodium chromate (CAS No. 7775-11-3), sodium dichromate (CAS No. 10588-01-9), ammonium dichromate (CAS No. 7789-09-5), potassium dichromate (CAS No. 7778-50-9). Draft, November 2002. Rapporteur United Kingdom.

Gibb, H.J., Lees, P.S., Pinsky, P.F., Rooney, B.C., 2000. Lung cancer among workers in chromium chemical production. Am. J. Ind. Med. 38, 115-126.

Hayes, R.B., Lilienfeld, A.M., Snell, L.M., 1979. Mortality in chromium chemical production workers: a prospective study. Int. J. Epidemiol. 8, 365-374.

Health Effects Institute, 1999. Diesel emissions and lung cancer: epidemiology and quantitative risk assessment. A special report of the institute's diesel epidemiology expert panel. Health Effects Institute, Cambridge, MA.

Heederik, D., Attfield, M., 2000. Characterization of dust exposure for the study of chronic occupational lung disease: a comparison of different exposure assessment strategies. Am. J. Epidemiol. 151, 982-990.

Hertz-Picciotto, I., Hu, S.W., 1994. Contribution of cadmium in cigarettes to lung cancer: an evaluation of risk assessment methodologies. Arch. Environ. Health 49, 297-302. 
Hertz-Picciotto, I., 1995. Epidemiology and quantitative risk assessment: a bridge from science to policy. Am. J. Public Health 85, 484-491.

International Agency for research on Cancer, 1990. Chromium and chromium compounds. IARC Monographs on the Evaluation of Carcinogenic Risks to Humans, Vol. 49. Chromium, Nickel and Welding. International Agency for Research on Cancer, Lyon, France, pp. 463-474.

Kauppinen, T.P., 1994. Assessment of exposure in occupational epidemiology. Scand. J. Work Environ. Health 20, Spec. No. 19-29.

Klimisch, H.J., Andreae, M., Tillmann, U., 1997. A systematic approach for evaluating the quality of experimental toxicological and ecotoxicological data. Regul. Toxicol. Pharmacol. 25, 1-5.

Korte, J.E., Hertz-Picciotto, I., Schulz, M.R., Ball, L.M., Duell, E.J., 2000. The contribution of benzene to smoking-induced leukemia. Environ. Health Perspect. 108, 333-339.

Kromhout, H., Loomis, D.P., Kleckner, R.C., 1999. Uncertainty in the relation between exposure to magnetic fields and brain cancer due to assessment and assignment of exposure and analytical methods in dose-response modeling. Ann. NY Acad. Sci. 895, $141-155$.

Kuo, J., Linkov, I., Rhomberg, L., Polkanov, M., Gray, G., Wilson, R., 2002. Absolute risk or relative risk? A study of intraspecies and interspecies extrapolation of chemical-induced cancer risk. Risk Anal. 22, $141-157$.

Langard, S., Andersen, A., Ravnestad, J., 1990. Incidence of cancer among ferrochromium and ferrosilicon workers: an extended observation period. Br. J. Ind. Med. 47, 14-19.

Mancuso, T.F., 1975. Consideration of Chromium as an industrial carcinogen. Conference Proceedings. International Conference on Heavy Metals in the Environment, Toronto, Ontario, Canada.

Mancuso, T.F., 1997. Chromium as an industrial carcinogen: Part I. Am. J. Ind. Med. 31, 129-139.

Money, C.D., Margary, S.A., 2002. Improved use of workplace exposure data in the regulatory risk assessment of chemicals within Europe. Ann. Occup. Hyg. 46, 279-285.

Moolgavkar, S.H., Moller, H., Woodward, A., 1999. Principles of the epidemiological approach to QEP. In: Moolgavkar, S., Krewski, D., Zeise, L., Cardis, E., Moller, H. (Eds.), Quantitative estimation and prediction of human cancer risks. International Agency for Research on Cancer, Lyon, pp. 61-73.

Norat, T., Bingham, S., Ferrari, P., Slimani, N., Jenab, M., Mazuir, M., Overvad, K., Olsen, A., Tjonneland, A., Clavel, F., Boutron-Ruault, M.C., Kesse, E., Boeing, H., Bergmann, M.M., Nieters, A., Linseisen, J., Trichopoulou, A., Trichopoulos, D., Tountas, Y., Berrino, F., Palli, D., Panico, S., Tumino, R., Vineis, P., Bueno-de-Mesquita, H.B., Peeters, P.H., Engeset, D., Lund, E., Skeie, G., Ardanaz, E., Gonzalez, C., Navarro, C., Quiros, J.R., Sanchez, M.J., Berglund, G., Mattisson, I., Hallmans, G., Palmqvist, R., Day, N.E., Khaw, K.T., Key, T.J., San, J.M., Hemon, B., Saracci, R., Kaaks, R., Riboli, E., 2005. Meat, fish, and colorectal cancer risk: the European Prospective Investigation into cancer and nutrition. J. Natl. Cancer Inst. 97, 906-916.

Rothman, K.J., 2002. Epidemiology. An introduction. Oxford University Press, New York.

Rothman, K.J., Greenland, S., 1998. Modern Epidemiology, second ed. Lippincott-Raven Publishers, Philadelphia.

Rushton, L., 2000. Reporting of occupational and environmental research: use and misuse of statistical and epidemiological methods. Occup. Environ. Med. 57, 1-9.

Samet, J.M., Schnatter, R., Gibb, H., 1998. Epidemiology and risk assessment. Am. J. Epidemiol. 148, 929-936.

Sanner, T., Dybing, E., Willems, M.I., Kroese, E.D., 2001. A simple method for quantitative risk assessment of non-threshold carcinogens based on the dose descriptor T25. Pharmacol. Toxicol. 88, 331-341.

Scientific Committee on Occupational Exposure Limits, 2003. Recommendation from the Scientific Committee on Occupational Exposure Limits: Risk Assessment for Hexavalent Chromium.
Seixas, N.S., Robins, T.G., Becker, M., 1993. A novel approach to the characterization of cumulative exposure for the study of chronic occupational disease. Am. J. Epidemiol. 137, 463-471.

Seixas, N.S., Checkoway, H., 1995. Exposure assessment in industry specific retrospective occupational epidemiology studies. Occup. Environ. Med. 52, 625-633.

Semple, S.E., Proud, L.A., Tannahill, S.N., Tindall, M.E., Cherrie, J.W., 2001. A training exercise in subjectively estimating inhalation exposures. Scand. J. Work Environ. Health 27, 395-401.

Shore, R.E., 1995. Epidemiologic data in risk assessment-imperfect but valuable. Am. J. Public Health 85, 474-476.

Smith, T.J., 2002. Issues in exposure and dose assessment for epidemiology and risk assessment. Hum. Ecol. Risk. Assess. 8, 1267-1293.

Sorahan, T., Burges, D.C., Hamilton, L., Harrington, J.M., 1998a. Lung cancer mortality in nickel/chromium platers, 1946-95. Occup. Environ. Med. 55, 236-242.

Sorahan, T., Hamilton, L., Gompertz, D., Levy, L.S., Harrington, J.M., 1998b. Quantitative risk assessments derived from occupational cancer epidemiology: a worked example. Ann. Occup. Hyg. 42, $347-352$.

Stayner, L., Smith, R., Bailer, A.J., Luebeck, E.G., Moolgavkar, S.H., 1995. Modeling epidemiologic studies of occupational cohorts for the quantitative assessment of carcinogenic hazards. Am. J. Ind. Med. 27, 155-170.

Stayner, L., Bailer, A.J., Smith, R., Gilbert, S., Rice, F., Kuempel, E., 1999a. Sources of uncertainty in dose-response modeling of epidemiological data for cancer risk assessment. Ann. NY Acad. Sci. 895, 212-222.

Stayner, L., Smith, R.J., Gilbert, S., Bailer, A.J., 1999b. Epidemiologic approaches to risk assessment. Inhal. Toxicol. 11, 593-601.

Stayner, L.T., Dankovic, D.A., Smith, R.J., Gilbert, S.J., Bailer, J., 2000. Human cancer risk and exposure to 1,3-butadiene - a tale of mice and men. Scand. J. Work. Environ. Health 26, 322-330.

Stayner, L., Steenland, K., Dosemeci, M., Hertz, P.I., 2003. Attenuation of exposure-response curves in occupational cohort studies at high exposure levels. Scand. J. Work. Environ. Health 29, 317-324.

Steenland, K., Loomis, D., Shy, C., Simonsen, N., 1996. Review of occupational lung carcinogens. Am. J. Ind. Med. 29, 474 490.

Steenland, K., Spaeth, S., Cassinelli, R., Laber, P., Chang, L., Koch, K., 1998. NIOSH life table program for personal computers. Am. J. Ind. Med. 34, 517-518.

Steenland, K., Deddens, J.A., 2004. A practical guide to dose-response analyses and risk assessment in occupational epidemiology. Epidemiology $15,63-70$.

Steenland, K., Greenland, S., 2004. Monte Carlo sensitivity analysis and Bayesian analysis of smoking as an unmeasured confounder in a study of silica and lung cancer. Am. J. Epidemiol. 160, 384-392.

Stewart, P., 1999. Challenges to retrospective exposure assessment. Scand. J. Work Environ. Health 25, 505-510.

Stroup, D.F., Berlin, J.A., Morton, S.C., Olkin, I., Williamson, G.D., Rennie, D., Moher, D., Becker, B.J., Sipe, T.A., Thacker, S.B., 2000. Metaanalysis of observational studies in epidemiology - A proposal for reporting. JAMA 283, 2008-2012.

Thomas, D., Darby, S., Fagnani, F., Hubert, P., Vaeth, M., Weiss, K., 1992. Definition and estimation of lifetime detriment from radiation exposures: principles and methods. Health Phys. 63, 259-272.

Tielemans, E., Marquart, H., De Cock, J., Groenewold, M., van Hemmen, J., 2002. A proposal for evaluation of exposure data. Ann. Occup. Hyg. $46,287-297$.

U.S. Environmental Protection Agency, 1986. Guidelines for carcinogenic risk assessment. Fed. Regist. 51, 33992-34001.

U.S. Environmental Protection Agency, 1998. Toxicological Review of Hexavalent Chromium (CAS No. 18540-29-9) in support of summary information on the Integrated Risk Information System (IRIS). U.S. Environmental Protection Agency, Washington, DC.

U.S. Environmental Protection Agency, 2005. Guidelines for Carcinogen Risk Assessment. Washington, DC. http://cfpub.epa.gov/ncea/cfm/ recordisplay.cfm?deid $=116283$. 
van den Brandt, P., Voorrips, L., Hertz-Picciotto, I., Shuker, D., Boeing, H., Speijers, G., Guittard, C., Kleiner, J., Knowles, M., Wolk, A., Goldbohm, A., 2002. Food safety in Europe (FOSIE): risk assessment of chemicals in food and diet. The contribution of epidemiology. Food Chem. Toxicol. 40, 387-424.

van Wijngaarden, E., Hertz-Picciotto, I., 2004. A simple approach to performing quantitative cancer risk assessment using published results from occupational epidemiology studies. Sci. Total Environ. 332, 81-87.

Verhagen, H., Feron, V.J., van Vliet, P.W., 1994, Risk assessment of peak exposure to genotoxic carcinogens, Health Council of the Netherlands, Den Haag.

Vermeire, T., Stevenson, H., Peiters, M.N., Rennen, M., Slob, W., Hakkert, B.C., 1999. Assessment factors for human health risk assessment: a discussion paper. Crit. Rev. Toxicol. 29, 439-490.
Visser, O., Coebergh, J.W.W., Schouten, L.J., Dijck, J.A.A.M.v., 2001. Incidence of cancer in the Netherlands 1997. Vereniging van Integrale Kankercentra, Utrecht

Voorrips, L.E., Goldbohm, R.A., Verhoeven, D.T.H., Poppel, G.A.F.C.v., Sturmans, F., Hermus, R.J.J., van den Brandt, P.A., 2000. Vegetable and fruit consumption and lung cancer risk in the Netherlands Cohort Study on diet and cancer. Cancer Causes Control 11, 101-115.

WHO, 2000a. Chromium. Air quality guidelines - second ed. WHO Regional Office for Europe, Copenhagen, Denmark.

WHO, 2000b. Evaluation and use of epidemiological evidence for environmental health risk assessment: WHO guideline document. Environ. Health Perspect. 108, 997-1002.

Wong, O., Raabe, G.K., 1996. Application of meta-analysis in reviewing occupational cohort studies. Occup. Environ. Med. 53, 793-800. 